\title{
Study of Various Routing Protocols in VANET
}

\author{
Ashutosh Kumar Choudhary, \\ Assistant Professor (CSE) \\ Amity University, Chhattisgarh
}

\begin{abstract}
Vehicular ad hoc Networks (VANET) could be a taxonomic category of Mobile unintended networks that provides a distinguished approach for Intelligent Transport System (ITS). The survey of routing protocols in VANET is vital and necessary for sensible ITS. This paper discusses the benefits / disadvantages and also the applications of varied routing protocols for transport unexpected networks. It explores the motivation behind the designed, and traces the evolution of those routing protocols. Finally the paper concludes by a tabular comparison of the assorted routing protocols for VANET.
\end{abstract}

Keywords: VANET, routing protocols, QoS, V2V, V2I

\section{Introduction}

Vehicular networks represent a very new category of wireless unexpected networks that alter vehicles to speak with one another and/or with edge infrastructure. Earlier, drivers were victimization their voice, gestures, horns, and observation of every other's mechanical phenomenon to manage their behavior. Once the forceful increase of vehicles created this not enough to manage, within the half of the nineteenth century, traffic police took charge of dominant and managing the traffic victimization hand signals, semaphores and coloured lights. The Nineteen Thirties saw the automation of traffic signals and within the Nineteen Forties automotive indicators were deployed wide. Variable-message signs were introduced within the Sixties to supply info to the drivers to adapt consistent with the present circumstances. The knowledge communicated via all of those means that is, however, terribly less: road infrastructure generally provides the similar info to any or all cars, and also the quantity of data that the drivers will share directly with each other is restricted. Recently, drivers will exchange additional info, like traffic info and directions, to every alternative via automotive phones or citizen band radio. Wireless communication supports more custom and complete info to be changed. VANET addresses of these problems related to the communications between vehicles and on-going analysis with wireless communication. It conjointly covers the aspects of Wireless Access for the transport setting (WAVE) standards supported the rising IEEE 802.11p specification. VANET basically enables infrastructure-to-vehicle (I2V), vehicle-to-infrastructure (V2I), and vehicle-to-vehicle (V2V) communications.During this paper, I have use the term V2I to discuss with each I2V and V2I communication.

\section{NetworkArchitectures}

Wireless unexpected networks usually don't place confidence in fastened infrastructure for communication and dissemination of data. VANETs follow constant principle and apply it to the extremely dynamic setting of surface transportation. As shown in Fig. 1, the design of VANETs chiefly falls among 3 categories: pure cellular/WLAN, pure unexpected, and hybrid. VANETs might 
use fastened cellular gateways and WLAN / WiMax access points at traffic intersections to attach to the net, to gather traffic info, or for routing functions. The spec below this situation may be a pure cellular or WLAN structure as shown in Fig. 1(a). VANETs will mix each cellular network Associate in Network and WLAN to form the networks so a WLAN is employed wherever an access purpose is offered and a $3 \mathrm{G}$ connection otherwise

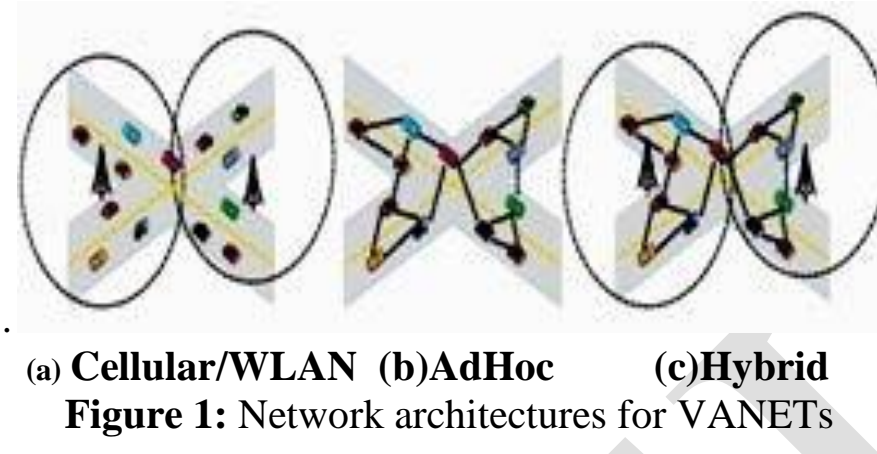

Stationary or fastened gateways around the sides of roads might give connectivity to mobile nodes (vehicles),Wireless unexpected networks usually don't place confidence in fastened infrastructure for communication and dissemination of datanodes (vehicles), but are eventually unfeasible considering the infrastructure costs involved. . In such a situation, all vehicles and road-side wireless devices will type a pure mobile unexpected network (Fig. 1(b)) to perform vehicle to vehicle communications and reach bound goals, like blind crossing.Hybrid design (Fig. 1(c)) of mixing infrastructure networks and unexpected networks along has conjointly been a doable resolution for VANETs.Namboodiri et al. [13] planned such a hybrid design,that uses some vehicles with each WLAN and cellular capabilities because the gateways and mobile network routers so that vehicles with solely WLAN capability will communicate with them through multi-hop links to stay connected to the globe. The hybrid design will give higher coverage, however conjointly causes new issues, like the seamless transition of the communication among completely different wireless systems.

\section{Layered View of Vehicular Networks}

Vehicular networks will be classified on the premise of 5 completely different aspects as shown in table.

Vehicular Networks has the varied vary of applications that varies safety applications to comfort applications

Safety Applications enhances the driving conditions and reduces the chances of accidents by providing enough time to the driver and applying the brakes automatically. These can be further divide into the following:

- Cooperative collisionwarning

- Incident management

- Emergency video streaming

Intelligent transport applications aim at providing quicker delivery of traffic info and up the potency and accuracy of traffic detection by permitting cooperative process of data between vehicles. These applications specialize in observant the traffic pattern and managing traffic consequently. 
Table 1: Layered View of vehicular networks

\begin{tabular}{|c|c|c|c|c|}
\hline \multirow{11}{*}{$\begin{array}{l}\text { Vehicular } \\
\text { Network }\end{array}$} & Application Type & \multicolumn{3}{|c|}{$\begin{array}{l}\text { - } \text { Safety application } \\
\text { - Intelligent transport application } \\
\text { - } \quad \text { Comfort application }\end{array}$} \\
\hline & Quality of Service & \multicolumn{3}{|l|}{$\begin{array}{ll}\text { - } & \text { Non-real-time } \\
\text { - } & \text { Soft-real-time } \\
\text { - } & \text { Hard-real-time }\end{array}$} \\
\hline & Scope & \multicolumn{3}{|l|}{$\begin{array}{ll}\text { - } & \text { Widearea } \\
\text { - } & \text { Local } \\
\end{array}$} \\
\hline & Network Type & \multicolumn{3}{|c|}{$\begin{array}{ll}- & \text { Ad hoc } \\
- & \text { Infrastructure- based }\end{array}$} \\
\hline & Communication Type & \multicolumn{3}{|l|}{ 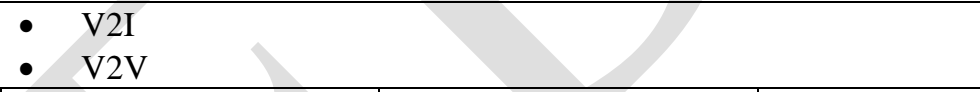 } \\
\hline & & \multicolumn{2}{|c|}{ Application Type } & $\begin{array}{l}\text { - Safety applic } \\
\text { - Intelligent tra } \\
\text { - Comfort appl }\end{array}$ \\
\hline & & Quality of Service & \multicolumn{2}{|c|}{$\begin{array}{l}\cdot \text { Non-real-time } \\
\text { - Soft-real-time } \\
\cdot \text { Hard-real-time }\end{array}$} \\
\hline & & & \multicolumn{2}{|c|}{$\begin{array}{l}\text { - Wide area } \\
\text { - Local }\end{array}$} \\
\hline & & Network Type & \multicolumn{2}{|c|}{$\begin{array}{l}\text { - Ad hoc } \\
\text { - Infrastructure-based }\end{array}$} \\
\hline & & Communicatio n Type & \multicolumn{2}{|l|}{$\begin{array}{l}\cdot \mathrm{V} 2 \mathrm{I} \\
\cdot \cdot \mathrm{V} 2 \mathrm{~V}\end{array}$} \\
\hline & & \multicolumn{3}{|l|}{ 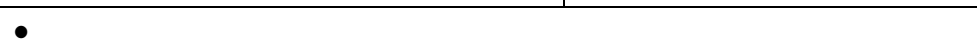 } \\
\hline
\end{tabular}

It will be additional classified into the following:

- Emergency video streaming

- TrafficMonitoring

- TrafficManagement

- Platooning

- Vehicletracking

- Notificationservices

Comfort applications are the applications of VANET associated with comfort level of the traveler acquiring the vehicle. It will be additional classified into the following:

- Parking placemanagement. 
- Distributed games and/ortalks.

- Peer to Peer applications

Consequently, the standard of Service needed for the network varies from non-real- time, to soft time period wherever a temporal order failure would possibly compromise service quality, up to onerous time period wherever a temporal order failure would possibly result in a catastrophe. These applications can even be exemplified by their scope, i.e., whether or not they give communication over a large space, or square measure native solely. Finally, such applications will vary in their networking approach: unexpected, wherever vehicles communicate suddenly, or infrastructure-based, wherever communication is ruled by fastened base stations. VANET has the communication type: Vehicle to Vehicle (V2V) and Vehicle to Infrastructure (V2I).

\section{VANET Characteristics, Issues And Requirements}

Wireless communication, significantly time period communication is extremely unreliable. additionally, VANET has bound distinctive problems that create it completely different from alternative wireless networks. As a result of no central coordination will be assumed, a

sole shared management channel is needed at the mac layer (the questionable one channel paradigm). quality movements of transport networks are terribly specific, e.g. vehicles move on the roads, in predefined directions, and this needs new specific quality models to be devised. Traditional quality models couldn't address the wants of VANET. Moreover, currently a day's cars are having terribly high quality rates then modification,so change in the topology in Associate in Nursing inDeterministic fashion that produces wireless transmission terribly difficult .

Furthermore, the vehicle density exhibits spatio-temporal variations: it would be terribly scarce (eg. Highway), with no vehicle or solely few, up to terribly dense (eg. city area), with over five hundred vehicles per $\mathrm{km}$. Each ends of the density spectrum square measure significantly difficult. The applications of transport networks ought to conjointly fulfill variety of nonfunctional needs, like doubtless terribly high liableness, however conjointly security to make sure that safety-critical applications can't be tempered with. Vehicles vary over terribly giant geographical areas (cities or countries), and so need doubtless large-scale networks, and particularly a really intensive preparation of apparatus if infrastructure- based mostly networks square measure used. Several VANET applications have either delay constraints or alternative QoS needs. Economical broadcasting of safety messages for obtaining full coverage and low latency to supply QoS and reliableness in VANET routing continues to be a difficult drawback [8]

Since quality of VANETs can't be captured by general quality models. Traffic flow (both in time and space) have to be compelled to be studied and integrated within the style of reliable and highperformance quality models.

Apart from this security is additionally one amongst the key problems in VANET. Cooperation among inter-vehicular networks and device networks placed among the vehicles or on the road have to be compelled to be additional investigated and analyzed. As the variety of vehicles grows the trust between them ought to even be maintained for the graceful communication.

In addition to technical challenges, socio- economic challenges ought to be solved. The advantages of $\mathrm{V} 2 \mathrm{~V}$ communication solely become vital once there square measure a sufficiently sizable amount of vehiclesvictimization the technology. Transport applications should so be ready to operate and be helpful despite initial low penetration.

\section{Overview of RoutingProtocols}

In VANET, the routing protocols square measure classified into 5 categories: Topology based routing protocol, Position based routing protocol, and Cluster based routing protocol, Geo solid routing 
protocol and Broadcast routing protocol. These protocols are characterized on the premise of space / application wherever they're best suited [1].

\section{a)Topology Based RoutingProtocols}

These routing protocols use links information that exists in the network to perform packet forwarding. They are further divided into Proactive and Reactive.

\section{i) Proactive routing protocols}

The proactive routing implies that the routing info, like next forwarding hop is maintained within the background regardless of communication requests. The advantage of proactive routing protocol is that there's no route discovery since the destination route is keep within the background, however the disadvantage of this protocol is that it provides low latency for real time application. A table is built and maintained among node. So that, every entry within the table indicates ensuing hop node towards a definite destination. It conjointly results in the upkeep of unused knowledge ways, that causes the reduction within theaccessible information measure the assorted styles of proactive routing protocols are: LSR, FSR.

\section{ii) Reactive/Ad hoc based routing}

Reactive routing opens the route only it's necessary for a node to speak with one another. It maintains solely the routes that are measure presently in use, as a result it reduces the burden within the network. Reactive routing consists of route discovery introduce that the question packets square measure flooded into the network for the trail search and this section completes once route is found. The assorted styles of reactive routing protocols square measure AODV, PGB, DSR and TORA

\section{b)Position Based Routing Protocols}

Position based routing consists of sophistication of routing rule. They share the property of victimization geographic positioning info so as to pick out ensuing forwarding hops. The packet is send with none map data to the one hop neighbor that is nearest to destination. Position based mostly routing is useful since no world route from supply node to destination node have to be compelled to be created and maintained. Position based routing is generally divided in 2 types: Position based greedy V2V protocols, Delay Tolerant Protocols.

\section{Position Based Greedy V2V Protocols}

In greedy strategy and intermediate node within the route forward message to the farthest neighbor within the direction of ensuing destination. Greedy approach needs that intermediate node ought to possessed position of itself, position of its neighbor and destination position. The goal of those protocols is to transmit knowledge packets to destination as before long as doable that's why these are called min delay routing protocols. Numerous styles of position based mostly greedy V2V protocols square measure GPCR, automotive and DIR

\section{GreedyPerimeter Coordinator Routing(GPCR)}

GPCR is predicated upon the actual fact that town street type a natural planner graph. GPCR doesn't need external static street map for its operation. GPCR consists of 2 components: A Restricted Greedy forwarding procedure, A repair strategy for routing rule. A GPCR follows a destination based mostly greedy forwarding strategy, it routes messages to nodes at intersection. Since GPCR doesn't use any external static street map therefore nodes at intersection square measure tough to seek out. GPCR uses heuristic methodology for locating nodes settled at intersections and designates those nodes as coordinators. organizer has the responsibility of creating routing selections. There square measure 2 approaches used for Organizerdetermination they're (a) Neighbor

Table Approach: The nodes sporadically transmit beacon messages that contains their position info and last noted position info of all neighbors, by being attentive to beacon messages a 
node as info concerning its own position, position of its neighbor and neighbor's neighbor. Victimization this info node $\mathrm{X}$ take into account itself to be among the intersection. (b) Parametric statistic approach: during this case node uses its position info and also the position info of its immediate neighbor to seek out the parametric statistic, pxy. This approach performs higher than neighbor table approach. B y victimization this approach the rule will avoid dependencies on external street map.

\section{Connectivity Aware Routing Protocols(CAR)}

CAR protocols notice a route to a destination; it's distinctive characteristics that it maintains the cache of flourishing route between numerous supply and destination pairs. It conjointly predicts the position of destination vehicle repairs route because the position changes. Nodes victimization automotive protocols send periodic salutation beacons that contain their rate vector info. On receiving salutation beacons a node can record sender in its neighbor table and calculate its own rate vector and rate vector of its neighbor. Beacons can even be piggybacked on forwarded knowledge packets to scale back wastage of information measure and congestion. Entries expire from the neighbor table once the space between nodes exceeds the brink worth. The CAR protocols establishes the notation of a guard that may be a geographic marker message, it's buffered and passed from one vehicle to a different to propagate the knowledge. Aguardis a temporary message that has Associate in Nursing ID, a TTL (Time to live) counts, a radius and a few state info. CAR provides 2 varieties of guards. The Standing guard and also the Traveling guard. Routing errors might occur owing to communication gap between anchor points or owing to guards. Therefore CAR protocol has 2 recovery methods to deal with the matter. The primary strategy is outing rule with active waiting cycle. The second strategy is walk around error recovery. The automotive protocol has the flexibility to come up with virtual info within the style of guards,that may be a distinct advantage over alternative protocols

\section{Diagonal-Intersection-BasedRouting Protocol(DIR)}

DIR protocol constructs a series of diagonal intersections between the supply and destination vehicle. The DIR protocol is predicated upon the geographic routing protocol during which supply vehicle geographically forwards the information packets towards the primary diagonal intersection, second diagonal intersection then on till the last diagonal intersection and at last geographically reaches to designation vehicle. DIR vehicle is auto adjustable, Auto adjustability implies that one sub path with low knowledge

packet delay between 2 neighboring diagonal intersections that is dynamically designated to forward knowledge packets to scale back the knowledge packet delay the route is mechanically designated with lowest sub path delay. DIR protocol will mechanically regulate routing path for keeping the lower packet delay.

\section{Delay TolerantProtocols}

In urban situation wherever vehicle are measure densely packed locating a node to hold a message isn't a tangle however in rural road scenario or in cities at night time fewer vehicles are measure running and establishing finish to finish route is tough. Therefore in such cases bound thought has to lean in distributed networks. The assorted styles of Delay Tolerant Protocols square measure MOVE,VADD, and SADV.

\section{Motion Vector Routing Algorithm}

The MOVE Algorithm is rule for distributed VANET situation. In these eventualities vehicle act as mobile router that have intermittent property with alternative vehicles. Affiliation opportunities should be scrutinized rigorously since they occur sometimes and world topology is additionally chop-chop changes. The rule should predict whether or not forwarding message can give progress toward meant destination. M OVE rule assumes that every node has data of its own position, heading and 
destination. From this info the present vehicle node will calculate theclosest distance between the vehicle and message destination. M OVE rule use less buffer house. MOVE rule is specially designed for distributed networks and for vehicles that transfer knowledge fromdevice networks to base station.

\section{Vehicle Assisted Data Delivery (VADD)}

VADD uses a carry and forward strategy to permit packets to be carried by vehicle in distributed networks for forwarding once the node enters the published vary, thereby permitting a packet to be forwarded by relay just in case of distributed networks. VADD need every vehicle to grasp its own position associate in nursing conjointly need an external static street map. Each packet has 3 modes: Intersection, Straight approach and Destination, where every mode is predicated on the situation of the node carrying the packet. Intersection mode is employed once the packet has reached Associate in nursing intersection at that routing selections will be created for the packet to be forwarded to a vehicle on any of the accessible directions of the intersection. In Straight approach mode the present node is on a road wherever there square measure solely 2 doable directions for the packet to travel, within the direction of the present node or within the wrong way. Destination mode is once the packet is near its final destination

\section{8.)StaticNodeAssisted Adaptive Routing Protocol(SADV)}

SADV aims at reducing message delivery delay in distributed networks. SADV conjointly dynamically adapts to variable traffic density by permitting every node to live the quantity of your time for message delivery. S ADV assumes that every vehicle is aware of its position through GPS and every vehicle has accessed to external static street map. SADV has 3 completely different modules; Static Node motor-assisted Routing (SNAR), Link Delay Update (LDU) and Multipath knowledge Dissemination (MPDD). SADV operates in 2 modes: "In Road Mode" and "Intersection Mode". SNAR create use of best ways, that square measure determined on the premise of graph abstracted from road map. LDU maintains the delay matrix dynamically by measurement the delay of message delivery between static nodes. MPDD helps in multipath routing

\section{a) Cluster BasedRouting}

Cluster based mostly routing is most well-liked in clusters. A bunch of nodes identifies themselves to be a district of cluster and a node is selected as cluster head can broadcast the packet to cluster. Smart quantifiability will be provided for big networks however network delays andoverhead square measure incurred once forming clusters in extremely mobile VANET. In cluster based mostly routing virtual network infrastructure should be created through the agglomeration of nodes so as to supply quantifiability. The assorted Clusters based mostly routing protocols square measure COIN and LORA_CBF

\section{b) Broadcast Routing}

Broadcast routing is often utilized in VANET for sharing, traffic,weather and emergency, road conditions among vehicles and delivering advertisements and announcements. The assorted Broadcast routing protocols square measure BROADCOMM, UMB, V-TRADE, and DV-CAST.

\section{c)Geo Cast Routing}

Geo Cast routing is largely a location based mostly multicast routing. Its objective is to deliver the packet from supply node to any or all alternative nodes among a nominal nation (Zone of connection ZOR). In Geo solid routing vehicles outside the ZOR don't seem to be alerted to avoid supernumerary hasty reaction. Geo solid is taken into account as a multicast service among a selected region. It usually defines a forwarding zone wherever it directs the flooding of packets so as to scale back message overhead and network congestion caused by merely flooding packets everyplace. Within the destination zone, unicast routing will be accustomed forward the packet. One pitfall of Geo solid is 
network partitioning and conjointly unfavorable neighbors, which can hinder the right forwarding of messages. The assorted Geo solid routing protocols square measure IVG, DG-CASTOR and DRG

\section{Conclusion}

In this section we've got reviewed existing routing protocols. Table a pair of provides a Comparison of those protocols. Previous forwarding methodology describes the primary routing call of the protocol once there square measure packets to be forwarded. Just in case of Delay finite protocols the previous forwarding methodology is employed, whereas all told alternative routing protocols wireless multi hop methodology of forwarding is employed. Digital map provides street level map and traffic statistics like traffic density and vehicle speed on road at completely different times. Digital map is obligatory just in case of a number of Cluster based mostly Routing Protocols. Virtual Infrastructure is made through agglomeration of nodes so as to supply quantifiability. Every cluster will have a cluster head that is accountable for secure communication between inter-cluster and intracluster coordination within the network. Recovery strategy is employed to pass though unfavorable things. Recovery strategy is that the criteria, that is employed to evaluate the performance of protocol.

Table 2: Comparison of Various Protocols

\begin{tabular}{|c|c|c|c|c|c|c|c|}
\hline Protocols & $\begin{array}{l}\text { Proactive } \\
\text { Protocols }\end{array}$ & $\begin{array}{l}\text { Reactive } \\
\text { Protocols }\end{array}$ & $\begin{array}{c}\text { Position } \\
\text { based } \\
\text { Greedy } \\
\text { Protocols }\end{array}$ & \begin{tabular}{|l} 
Delay \\
Bounded \\
Protocols
\end{tabular} & $\begin{array}{c}\text { Cluster } \\
\text { Based } \\
\text { Protocols }\end{array}$ & $\begin{array}{l}\text { Broadcast } \\
\text { Protocols }\end{array}$ & $\begin{array}{l}\text { Geo cast } \\
\text { Protocols }\end{array}$ \\
\hline $\begin{array}{c}\text { Prior } \\
\text { Forwarding } \\
\text { Method } \\
\end{array}$ & $\begin{array}{l}\text { Wire less } \\
\text { multi hop } \\
\text { Forwarding } \\
\end{array}$ & $\begin{array}{l}\text { Wire less } \\
\text { multi hop } \\
\text { Forwarding } \\
\end{array}$ & $\begin{array}{l}\text { Feuristic } \\
\text { method }\end{array}$ & $\begin{array}{l}\text { Carry \& } \\
\text { Forward }\end{array}$ & $\begin{array}{c}\text { Wireless } \\
\text { Multihop } \\
\text { Forwarding } \\
\end{array}$ & $\begin{array}{l}\text { Wire less } \\
\text { multi hop } \\
\text { Forwarding }\end{array}$ & $\begin{array}{l}\text { Wire less } \\
\text { multi hop } \\
\text { Forwarding }\end{array}$ \\
\hline $\begin{array}{l}\text { Digital Map } \\
\text { Requirement }\end{array}$ & No & No & No & No & Yes & No & No \\
\hline \begin{tabular}{|c|} 
Virtual \\
Infrastructure \\
Requirement \\
\end{tabular} & No & No & No & No & Yes & No & No \\
\hline \begin{tabular}{|c|} 
Realistic \\
Traffic Flow \\
\end{tabular} & Yes & Yes & Yes & No & No & Yes & Yes \\
\hline $\begin{array}{l}\text { Recovery } \\
\text { Strategy }\end{array}$ & $\begin{array}{l}\text { Multi Hop } \\
\text { Forwarding }\end{array}$ & $\begin{array}{l}\text { Carry \& } \\
\text { Forward }\end{array}$ & $\begin{array}{l}\text { Carry \& } \\
\text { Forward }\end{array}$ & $\begin{array}{l}\text { Multi hop } \\
\text { Forwarding }\end{array}$ & $\begin{array}{l}\text { Carry \& } \\
\text { Forward }\end{array}$ & $\begin{array}{l}\text { Carry \& } \\
\text { Forward }\end{array}$ & Flooding \\
\hline Scenario & Urban & Urban & Urban & Sparse & Urban & Highway & Highway \\
\hline
\end{tabular}

\section{References:-}

[1] A Comparative study of MANET and VANET Environment". Journal of Computing 2 (7). 7 2010. Retrieved 28 October 2013.

[2] J. Gozalvez, M. Sepulcre and R. Bauza, "IEEE 802.11p Vehicle to Infraestructure Communications in Urban Environments", IEEE Communications Magazine, vol. 50, no. 5,pp. 176183, May 2012.

[3] J. Gozalvez, M. Sepulcre and R. Bauza, "IEEE 802.11p Vehicle to Infraestructure Communications in Urban Environments", IEEE Communications Magazine, vol. 50, no. 5,pp. 176183, May 2012.

[4] ON World Inc., Wireless Sensor Networks: Growing Markets, Accelerating Demands, Jul. 2005. 
[Online]. Available:http://www.onworld.com/html/wirelesssensorsrprt2.

[5] Embedded WiSeNTs Consortium, Embedded WiSeNTs Research Roadmap (Deliverable 3.3). [Online]. Available: http://www. embedded-wisents.org/

[6] L. M. Bergasa, J. Nuevo, M. A. Sotelo, R. Barea, and M. E. Lopez,"Real-time system for monitoring driver vigilance," IEEE Trans. Intell.Transport. Syst., vol. 7, no. 1, pp. 63-77, Mar. 2006.

[7] Boon-Giin Lee and Wan-Young Chung, "Driver Alertness Monitoring Using Fusion of Facial Features and Bio-Signals” IEEE SENSORS JOURNAL, VOL. 12, NO. 7, JULY 2012.

[8] Jiangpeng Dai * t , Jin Teng t, Xiaole Bai t, Zhaohui Shen:j: and Dong Xuan t "Mobile Phone Based Drunk Driving Detection".

[9] J. Lee, J. Li, L. Liu and C. Chen, "A Novel Driving Pattern Recognition and Status Monitoring System", in First pacific rim symposium, PSIVT 2006, pp. 504-512, December 2013.

[10] Claudia Campolo, Antonio Iera, Antonella Molinaro, Stefano Yuri Paratore," SMaRTCaR: An Integrated Smartphone-based Platform to Support Traffic Management Applications" 2012 IEEE. 